\title{
Food Consumption Habits and Nutritional Status of Women and Infants
}

\author{
Tanka Maya Pokharel*
}

\begin{abstract}
This paper attempts to find-out the existing knowledge of nutrition on food consumptions and dietary practices of women and infants. I have used the systematic review of the Hinari database which were published from 2012 April to 2018.These data show that women and infant food consumption behaviour and nutrition status is directly related to family food consumptions. Research shows that low cobalamin and folic acid was found in women before they conceive and folate deficiency was uncommon on food consumptions. Low intakes of iron are consistent with a high prevalence of anaemia seen in the six to twenty-four months of children. Food beliefs and practices tend to reduce women's consumption of micronutrient-rich foods, such as dietary restrictions during menstruation, pregnancy and lactation. The research shows that are overlapping with these beliefs and practices on intra household allocation of food. The poor dietarypractice among pregnant women which ranges from 39.3 percent to 66.1 percent have limited nutritional knowledge and wrong perception towards dietary behaviour. It was also found that basis underweight is greater in rural areas ( 3 I percent) than in urban areas (23percent). Those children whose mothers are illiterate are more than twice as likely to be underweight than the children whose mothers have at least basic education.
\end{abstract}

Key words: Dietary practice, food consumption, food behaviour and practice deficiency, nutritional knowledge.

\section{Introduction}

Nutrition is the intake of food considered in relation to the body's dietary needs. It is also the science that deals with the digestion, absorption and metabolism of food that is the utilization of food in the body. Good nutrition, an adequate, well balanced diet combined with regular physical activity is cornerstone of good health. Poor nutrition can lead to reduced immunity. Increased susceptibility to disease, impaired physical and mental development, and reproductively (WHO, 20I8).

Nutrients are constituents of food which helps to maintain our body function, growth and renewal of its components and to protect our organ. According to the AHS (2015/16), urban households consume about 1.7 times more than the rural households. Nepalese household expends Rs. 322730 per year on which $53.8 \%$ of per capita income is spent on consuming food. MOPE has also indicated the same data that is nearly 42.2 percent of the household's heads were in the age group 30 to 49 years but 25.9 percent households were headed by female who played the major role on food consumption decision making. The male members of reproductive age group population were 48.8 percent and 51.6 percent were females on which the total reproductive age population was 58.8 percent in Nepal (NDHS, 2016). Knowledge of

\footnotetext{
*PhD. Scholar, Graduate School of Education, TU, FoE Email: nita.pokharel99@gmail.com
} 
pregnancy finds the gap on new born care, low dietary diversity and micronutrient adequacy is observed among lactating women in a semi-urban area of Nepal.

\section{Methods}

Data were entered into an online database using standard abstraction items, one for existing reviews and reports and another for original research. To carry out this systematic review study, first of all, I made a search of the Henari database found in feeding practice of mother and infant nutritional status of mother and infant between2012- April to 2018which were sorted by national and international research. Amongthem, Ihad chosen ten research articles, six from feedingpractice of mother and infant and four from nutritional status of mother and infants. The reviewed literatures had different theoretical and philosophical bases such as Health Belief Model (HBM) which help to determine on the effect of nutrition belief based on health belief model on nutritional knowledge and dietary practice of pregnant women (Dissie, 2017).I had also correlated among the findings of reviewed articles. This paper has been prepared for the nutritional condition assessment for women and children. I have consulted different studies and web sites, such as WHO, Hinari, Research4life, Google Scholar and Proquet.

\section{Results and Discussions}

The detailed shape of the literature shows that women and infant nutrition towards the key theme areknowledge of nutrition and its relation with dietary behaviours, food consumption and dietary practices and impact of food consumption and dietary practice on nutrition basis of the systematic review.

\section{Knowledge of Nutrition and its Relation with Dietary Behaviours}

On the basis of knowledge of nutrition and its relation with dietary behaviours, Ethiopia study shows that poor dietary practice among pregnant women ranges from 39.3 percent to 66.1 percent. Limited nutritional knowledge and wrong perception towards dietary behaviours were underlying factors for that result. Similarly, IOM Australia has suggested, that folate is needed before 28 days of pregnancy. On the basis of baseline survey and lab test result, women in pregnancy period need more nutrients care but results showed that low folate was used in pregnancy (Opie et al.,20I6). HBM construct was assessed using five-point Likert scale for dietary knowledge and practice(Diddana, Kelkay, Dola, \& Sadore, 2018).Infants under six months should be exclusively breastfed but only 66 percent of the infants under six months were found to be breastfed (NDHS 2016).It was found that in addition to breast milk, six percent of these young infants consume plain water, six percentages consume non-milk liquids, 10 percent consume other milk and 12 percentages consume complementary foods. Only nine percent of infants under six months were fed using a bottle with a nipple.

Eighty-three percent of children aged six-eight months received timely complementary food (NDHS 2016).Survey shows that I0percent of children were wasted and two percent were severely wasted. On the basis of food consumption, children can be underweight for their age because they are stunted, wasted or both. Weight-for-age is an overall indicator of nutritional 
health. Research has used the waterloo classification for nutritional status.Food beliefs and practices tend to reduce women's consumption of micronutrient-rich foods, such as dietary restrictions during menstruation, pregnancy and lactation. Overlapping with these beliefs and practices overall intra household allocation of food is evident in the study communities.

\section{Food Consumption and Dietary Practices}

Girls mostly consume fruits, vegetables than boys but milk and snacks are more demanded by boys. Similarly, those people who sleep for short time can consume more food because of hormonal change of body and obesity(Westerlund et al ., 2009). Sleep length is not only the way to measure obesity.More study suggests to consume low alcohol who are planning pregnancy, it also suggests to intake good nutrients, exercise and avoid smoking (Campbell et al., 2016). The survey shows that general practices among 238 women who became pregnant within three months of being interviewed and the main outcome measures folic acid supplements intake, alcohol consumption, smoking, diet, and physical activity before pregnancy, hygiene value and gestational weight; pregnancy needs to be well nutrient. Seven feeding guidelines like grains roots and tubes, legumes nuts, dairy products, flesh foods, eggs, Vitamin "A" rich fruits and vegetables including other fruits and vegetables for better nutrition for women and infant (Van Esterik, 2012). Furthermore, it has suggested that infant should be consumed minimum four items in 24 hours ANC visit, nutrition, folate \& vitamins necessary for pregnancy.

Study was focused on pre-lacteal feeding and discarding colostrum. The research shows that there was a practice of providing all newborn babies with butter ghee, oil honey, sugar or animal milk before the initiation of breastfeeding. Nepalese study shows that complementary feeding in the form of home-made cereal based (Lito), animal or powder milk are commonly introduced from one month of life due to common belief that mother milk alone is not sufficient for their children (Henjum et al., 2015). Nutritional status of infant, food and nutrition program and institute of public health Mexico shows that adoption of recommended breastfeeding and complementary feeding behaviours along with the access to appropriate quality and quantity of foods are essential components for optimal nutrition of infants. Research shows that iron, zinc and vitamin B-6 are deficient in complementary food diets in Bangladesh. Low intakes of iron are consistent with a high prevalence of anaemia seen in infants (Lutter \& Rivera, 2003). More explore on intakes calcium, vitamin ' $A$ ', thiamine, folate and vitamin ' $C$ ' depends on the age range in question and set of requirements used in the assessment. There were high nutritional requirements relative to body size and small amount of foods. Complementary food diets are inadequate like iron, zinc and vitamin B-6. Riboflavin, niacin, calcium, thiamine, folate, vitamin $C$ and vitamin $A$ are also likely to be inadequate for them (Lutter \& Rivera, 2003).Dietary diversity is often defined as the number of certain food groups consumed by an individual or family (Declerck, 2016). Study has recommended that different age groups individual dietary diversity is related to increased nutrient adequacy of the diet. Dietary diversity was found positively correlated with the micronutrient for children. Association between dietary diversity and micronutrient uptake, ecological knowledge plays an 
important role in efforts to direct food systems at improved human nutrition. Determinantsof exclusive breast-feeding study were in Pokhara, Nepal among the eighty-five mothers who had delivered within two months shows that breast feeding factors, friends, types of delivery, cultural practices and baby. First fed also impacts on nutrition of infant (NDHS, 20I6). Cultural factors, food beliefs and practices tend to reduce women's consumption of micronutrient-rich foods such as dietary restrictions during menstruation, pregnancy and lactation. On beliefs and practices, an overall pattern of dis-favouritism of females in the intra household allocation of food is evident in the study communities. While staple food items like vegetables, meat, ghee, are often preferentially allocated to valued household members including adult males and small children (Gittelsohn et al., 1997).Antenatal care in Nepal shows that 4070 mothers who completed the seven recommend components like blood pressure, urine, syphilis, anaemia, iron supplements, worm infestations, tetanus toxic injection and health education were included in the basic criteria for antenatal care. ANC visit would improve the quality of women health but lack of education and poor economic status of women played a vital role in decreasing ANC visit which suggested health education and awareness to be in first priority before ANC. It was experienced 287,000 maternal deaths globally in a yearly (2010). Injury infection and morbidity were the main causes of the MMR in Nepal. Maternal mortality rate was $28 \mathrm{I} / 100000$ live birth. ANC visit decreased the anaemia, pregnancy, induced hypertension, preterm labour, promote positive pregnancy risk of low birth weight. The sample research shows that 29percent of women have received good ANC services (Joshi, Torvaldsen, Hodgson, \& Hayen, 20I4).

\section{Impact of Food Consumption and Dietary Practice on Nutrition}

Those people who sleep for short time can consume more food because of hormonal change of body and obesity (Westerlund, Ray, \& Roos, 2009). Research shows that low dietary diversity and micronutrient adequacy among lactating women in a semi-urban area of Nepal, the mean usual energy of lactating women intake was $8464 \mathrm{~kJ} / \mathrm{d}$. The main source of energy were protein, fat and carbohydrates that was found to be taken IIpercent, I3percent and 76percentage respectively(Henjum et al., 20I5). The micronutrient intake of lactating women was below the estimated average requirements of vitamin $C$ and Zink. About 60percentage of the energy intake was positively associated with dietary diversity, women's educational level and socio-economic status.

The low micronutrient intakes are probably explained by low dietary diversity and a low intake of micronutrient-rich foods (Henjum et al., 2015). The 201I DHS found that one in three children in Cameroon suffer from malnutrition. The study shows that I3percentage to I4percent children who were victims of severe malnutrition in 2004 increased chronically from 32percentage to 33percentage. UNICEF estimated that at least 105,000 children less than five years old died of malnutrition annually in Cameroon. Furthermore, 210,000 children less than 5 years suffered from chronic malnutrition with 120,000 of them living in the North and extreme North regions of the country (Vitalis et all., 2018). This study further suggested that nearly two thirds of infants below six months of age were introduced to homemade cereals 
(Lito) as complementary food whereas 10percentage and seven percentage introduced cereals (Henjum et al., 2015).A study on nutritional status and dietary practices on early pregnancy shows that Bangladeshi adolescents have little knowledge about nutrition. Among the 1552 pregnant adolescent, 36 percent had low body mass index, 28percentage were anaemic, I0percent had iron deficiency and 32percent had vitamin A deficiency. We can conclude that consumption of animal source foods was 10.3 times a week. Education socio economic status associated with dietary practice also affects on BMI on early pregnancy (Mridha, Matias, Arnold, \& Dewey, 2018).

Global Hunger with a population of I 24 billion and among them over 17 percentage of India's population was undernourished. Hungnam report $(20 \mathrm{II})$ also estimated that 42percentage of Indian children under 5 years of age were underweight which accounts for India having the highest number of undernourished children globally (Mridha et al., 2018). The Nepalese nutrition diet is shifting away from agricultural staple-based food to modern processed food with higher in total energy, total fat and sugar causing the overweight and diet related noncommunicable disease. Economic structure has also changed shifting from away on agricultural food supply system. The Nepalese diet are triggered by income and urbanization so far it causes the processed food, edible oil and sugar easily available at market and also fast food(Henjum et al., 2015). Research based on the nutritional status and food intake of cobalamin and folate among non-pregnant women of reproductive age group in Bhaktapur, Nepal shows that cobalamin and folate are especially important for women of childbearing age due to their overall role in foetal growth and development. On the base of research, cobalamin and folate use was lacking in Bhaktapur,Nepal (Chandyo et al., 2016). Research explains on the basis of blood samples from 500 non-pregnant women and their 24-h dietary recalls with food frequency questionnaires from a sub-sample of 379 women. It was found that 72 percent nutritional Cobalamin intake was daily whereas low cobalamin was found in 42 percent of the women; folate deficiency was uncommon on food consumption (Chandyo et al., 2016).

Pregnancy obesity and maternal nutritional status during pregnancy study was based on factor analysis conducted by USA. This research shows that pregnant women who are obese have more risk of pre-eclampsia. Study used BMI indicators on pre-pregnancy and before conception. It also suggested that obese generated various problems that women need to concentrate, to be aware from food intake (Tomedi et al., n.d.). Nepalese study shows that relationship between maternal nutritionalstatus, food intake and pregnancy weight gain is none related to the risk of low birth weight in Nepal. The cross-session study was used where altogether 376 women were selected among 27.9percentage delivery cases. When observed among them low birth weight was higher in rural than urban areas. Maternal protein intake $(r=0.05)(P<0.00 I)$, folate intake were significantly different in rural and urban areas(Acharya et al., 2016). 
Nepalese study shows that immunization reduced low birth weight and empowered under powered to detect reduction of public health importance. The research showed larger impact on birth weight on better vaccine. In this study, vaccination vs. saline was used among 3693 women. They were randomized placebo (1846) another influenza vaccine (1847) mothers with flu vaccine. On the basis of comparison of three countries, the research suggested that recommended foods and vegetables consumption per day is 25 percent in men and 29percent in women. In UK \& Germany, people recommended meat as good sources of nutrition. In China 18-30 year's women mainly recommended fruits, vegetables, sugar sweetened beverages as their major feeding practice.

Finally, the study shows that maternal influenza vaccination did not improve birth weight and reduce influenza infections. The effect was mild to moderate malnutrition of six month life protected from nutrient food.

\section{Conclusion}

Different studies show low nutritional status of infants and mother of different countries. The $\mathrm{BMI}$ of pregnant women is comparatively low as compared with standard BMI index. There is a wide variety of behaviours that is related to feeding practice of women and infant that promotes or prevents certain women and food consumption behaviours and nutrition status. Women's own food consumption behaviour strong correlates of infant food consumption behaviour. Some behaviours such as active and restrictive guidance are effective only in certain context, active being more effective in encouraging fruits and vegetables consumption, while restrictive guidance is more effective in discouraging unhealthy eating such alcohol, smoking, and junk food consumption. Low dietary diversity and micronutrient adequacy is observed among lactating women in a semi-urban area of Nepal. Even now a days there is no any provision to pregnant mother and infant for their nutrition right. Food security is most be launched in all over the country. Nutrition education program in the community should be launched as a health education programme.

\section{References}

Acharya, O., Zotor, F. B., Chaudhary, P., Deepak, K., Amuna, P., \& Ellahi, B. (2016). Maternal nutritional status, food intake and pregnancy weight gain in Nepal. Journal of Health Management, I8(I), I-12. https://doi.org//0.1 I77/ 09720634I5625537

Campbell, E. E., Dworatzek, P. D. N., Penava, D., de Vrijer, B., Gilliland, J., Matthews, J. I., \& Seabrook, J. A. (2016, January 8). Factors that influence excessive gestational weight gain: moving beyond assessment and counselling. Journal of Maternal-Fetal and Neonatal Medicine. https://doi.org/10.3109/14767058.2015.1/37894

Chandyo, R., Ulak, M., Sommerfelt, H., Schneede, J., Ueland, P., Strand, T., ... Strand, T. A. (2016). Nutritional Intake and Status of Cobalamin and Folate among Non-Pregnant Women of Reproductive Age in Bhaktapur, Nepal. Nutrients, 8(6), 375. https://doi.org// 0.3390/nu8060375 
Diddana, T. Z., Kelkay, G. N., Dola, A. N., \& Sadore, A. A. (2018). Effect of nutrition education based on health belief model on nutritional knowledge and dietary practice of pregnant women in Dessie Town, Northeast Ethiopia: A cluster randomized control trial. Journal of Nutrition and Metabolism, 2018. https://doi.org/I0.1 155/2018/6731815

Declerck, F. sA. J. (n.d.). S42. Retrieved from www.nutritiondata.com

Gittelsohn, J., Thapa, M., \& Landman, L. T. (1997). Cultural factors, caloric intake and micronutrient sufficiency in rural Nepali households. Social Science \& Medicine, 44(I I), 1739-1749. https://doi.org//0.1016/S0277-9536(96)00375-9

Henjum, S., Elin Torheim, L., Thorne-Lyman, A. L., Chandyo, R., Fawzi, W. W., Shrestha, P. S., \& Strand, T. A. (20I5). Low dietary diversity and micronutrient adequacy among lactating women in a peri-urban area of Nepal. Public Health Nutrition, I8(I7), 320I32 I0. https://doi.org/I0.10I7/S13689800I500067I

HHS. (20I8). Part E. Systematic review literature search methodology 2018 physical activity guidelines gdvisory committee scientific report E-I. Retrieved from https://health.gov/paguidelines/secondedition/report/pdf/06_E_Systematic_Review_Literature_Search_Methodology.pdf

Joshi, C., Torvaldsen, S., Hodgson, R., \& Hayen, A. (20I4). Factors associated with the use and quality of antenatal care in Nepal: a population-based study using the demographic and health survey data. BMC Pregnancy and Childbirth, I4(I), 94. https://doi.org//0.1 186/I47/-2393-I4-94 [doi]

Lutter, C. K., \& Rivera, J. A. (2003). Nutritional status of infants and young children and characteristics of their diets. The Journal of Nutrition, 133(9), 294IS-2949S. https://doi.org//0.1093/jn/I33.9.294IS

Mridha, M. K., Matias, S. L., Arnold, C. D., \& Dewey, K. G. (20I8). Factors associated with nutritional status and dietary practices of Bangladeshi adolescents in early pregnancy. Annals of the New York Academy of Sciences, 14/6, 66-76. https://doi.org/ https://dx.doi.org/I 0.1 I I I/nyas. I3568

NDHS, (2016). Nepal Population Report 2016. Ministry Of Population and Education (pp. I-232). Retrieved from http://www.mope.gov.np/downloadfile/Nepal Population Report 2016_I48I25985I.pdf

Opie, R. S., Neff, M., \& Tierney, A. C. (2016). A behavioural nutrition intervention for obese pregnant women: Effects on diet quality, weight gain and the incidence of gestational diabetes. Australian and New Zealand Journal of Obstetrics and Gynaecology, 56(4), 364373. https://doi.org/I0.1 I I I/ajo. 12474

Tomedi, L. E., Chang, C.-C. H., Newby, P. K., Evans, R. W., Luther, J. F., Wisner, K. L., \& Bodnar, L. M. (n.d.). Pre-pregnancy obesity and maternal nutritional biomarker status during pregnancy: a factor analysis. Public Health Nutrition, (8), |4|4-14|8. https://doi.org/I0.1017/SI368980013000736 
Van Esterik, P. (2002). Contemporary Trends in Infant Feeding Research. Annual Review of Anthropology, 3 I (I), 257-278. https://doi.org/ 10.1 I 46/annurev.anthro.3 I.040402.085428

Westerlund, L., Ray, C., \& Roos, E. (2009). Associations between sleeping habits and food consumption patterns among 10-1I-year-old children in Finland. British Journal of Nutrition, 102(I0), I53I. https://doi.org/I0.10I7/S0007II4509990730

WHO | Marketing of breast-milk substitutes: National implementation of the international code. (2018). WHO. Retrieved from http://www.who.int/nutrition/publications/ infantfeeding/code_report2018/en/ 